\title{
Arte contemporáneo y nuevos autoritarismos. Notas para una reflexión
}

\section{Contemporary Art and new Authoritarianisms. Notes for reflection}

Gabriel Rudas (Colombia)

gabrielrudas@gmail.com

Universidad Nacional de Colombia

\section{Resumen}

El autor presenta un paralelo entre el arte contemporáneo y las nuevas formas de autoritarismo. Cuestiona el concepto de libertad y plantea el placer como un sistema social de dominación. Rudas conecta el adoctrinamiento fascista del siglo XX y las nuevas formas de autoritarismo haciendo una comparación entre la publicidad de ese momento y la actual. Hace también una aproximación a ciertas formas de arte no hegemónico, como las propuestas de Ana Mendieta, Luis Caballero, Banksy y Doris Salcedo.

\begin{abstract}
The author makes a parallel between contemporary art and the new forms of authoritarianism. He questions the concept of freedom and states pleasure as a social system of domination. Rudas connects the fascist indoctrination of the XX century and the new forms of authoritarianism making a comparison between publicity at that time and in the present. He also makes an approach to some non-hegemonic art forms, such as Ana Mendieta, Luis Caballero, Bansky and Doris Salcedo's proposals.
\end{abstract}


- El arte contemporáneo y nuevos autoritarismos - Gabriel Rudas

Palabras clave: arte contemporáneo,

nuevos autoritarismos, hegemonía, Ana Mendieta, Luis Caballero, Banksy, Doris Salcedo, sistema social.
Keywords: contemporary art, new authoritarianisms, hegemony, Ana Mendieta, Luis Caballero, Bransky, Doris Salcedo, Social System 


\title{
Arte contemporáneo y nuevos autoritarismos. Notas para una reflexión
}

\author{
Gabriel Rudas (Colombia) \\ Profesional en Estudios literarios de la Universidad Nacional de Colombia. Máster en Li- \\ teratura hispanoamericanade la University of Cincinnati (Estados Unidos).
}

\section{Introducción}

Se nos dice que vivimos en un mundo libre - libre por la gracia de la tecnología, la democracia y los mercados-, que vivimos en un mundo conectado, en un tiempo global lleno de cambios vertiginosos donde solo la imaginación es el límite. Solo unos pocos países y unos cuantos fanáticos no han entendido lo que el nuevo mundo nos ofrece. Hace tiempo murió la última amenaza real de una dictadura totalitaria, y solo el extremismo religioso y algunos gobiernos vecinos anacrónicos se interponen en nuestro destino de formar una aldea global de razón y progreso. Se nos dice esto, y sin embargo, ¿qué tan libres somos? ¿Qué tan lejos estamos del autoritarismo que decimos haber desterrado?

\section{Las nuevas máscaras del pensamiento autoritario}

"Podría preciarme también de haber influido con mis películas en las costumbres italianas y en su evolución; en la liberalización de la opinión pública y en la descongestión del 'sentido común del pudor"', decía el escritor y cineasta Pier Paolo Pasolini (2010, p. 26), en una reflexión retrospectiva sobre su obra fílmica; pero luego sentenciaba: 
[...] pero de esto no me precio [...], me arrepiento de la influencia liberadora que mis películas eventualmente pudiesen haber tenido en las costumbres de la sociedad italiana. Ellas han contribuido, de hecho y en la práctica, a una falsa liberación, querida en realidad por un nuevo poder reformador permisivo, que es sin más el poder más fascista que la historia recuerde ( 2010, p. 26).

Famoso por sus escandalosas películas, llenas de transgresiones a la moral sexual de su tiempo, esta afirmación es por lo menos desconcertante. No se trata de un acto de mea culpa, de una negación de sus propias intenciones de ruptura; se trata de la verificación de un hecho que se empezó a perfilar desde mediados del siglo XX y que hoy en día es la realidad dominante: el placer, tanto el sexual como el de la satisfacción de cualquier deseo se ha convertido en la prisión más efectiva para el sujeto; en una manera mucho más audaz y potente de anular la diferencia y mantener funcionando un sistema social de dominación.

La libertad que pregona el discurso del capitalismo tardío no es la que propusieron los ilustrados, y la realización del sujeto en el placer no es el éxtasis que soñaron los utopistas y los místicos. Las antiguas utopías por las que se derramaba la sangre de otros y se anulaba la diferencia, los bellos ideales que generaron el horror del siglo XX, han sido reemplazadas por el culto a la satisfacción del deseo. No se percibe el deseo como el producto de un descubrimiento del sujeto, sino como una navegación sin fin por una sobrecarga de símbolos que se presentan como soluciones y promesas de satisfacción, pero que pronto se vuelven ideales, obligaciones y formas de control.

Esto nos hace poner en duda la creencia de que las formas de control autoritario hayan realmente desaparecido en las autoproclamadas culturas civilizadas. En las sociedades occidentales (incluso en nuestra supuesta versión de "Occidente de segunda clase"), el totalitarismo parece pertenecer al pasado. Sin embargo, si vamos más allá de las definiciones estrictas del totalitarismo (es decir, las que lo entienden en cuanto régimen de gobierno o proceso histórico concreto), debemos preguntarnos no solo por sus manifestaciones particulares, sino también por el tipo de pensamiento que permitió su emergencia.

Detrás de los totalitarismos del siglo XX hubo unas circunstancias 
históricas particulares, y el hecho de que no se hayan repetido es muestra justamente de qué tan anclados estaban a ciertas configuraciones sociales. Estas circunstancias y configuraciones se han transformado (en parte debido a los totalitarismos mismos). Pero la cuestión no es tan clara si deliberamos en el pensamiento que los hizo posibles, es decir, en ese conjunto de formas de concebir la realidad social, la política y la relación del sujeto con el poder y con lo colectivo. Si tomamos esta perspectiva amplia, deja de ser un hecho indiscutible que ese autoritarismo haya desaparecido de la cultura. Aun cuando no encontremos un régimen totalitario al pie de la letra, el pensamiento autoritario, sus métodos y sus consecuencias, siguen estando presentes.

¿Cómo opera el autoritarismo contemporáneo, sobre todo cuando la represión no se manifiesta en formas evidentes? El concepto de hegemonía, que definió Antonio Gramsci y retomó el crítico cultural Raymond Williams, ayuda a explicar este proceso:

Gramsci planteó una distinción entre "dominio" y "hegemonía". El "dominio" se expresa en formas directamente políticas, sociales y en tiempos de crisis por medio de una coerción directa o efectiva. Sin embargo, la situación más habitual es un complejo entrelazamiento de fuerzas políticas, sociales y culturales (Williams, 1998, p. 129).

La hegemonía es, entonces, un entrelazamiento de prácticas y sistemas sociales que se caracterizan por sostener un sistema de dominación. Pero, como advierte Williams más adelante, la hegemonía se caracteriza también por ser ella misma una dominación:

[...] la hegemonía constituye todo un cuerpo de prácticas y expectativas en relación con la totalidad de la vida: nuestros sentidos y dosis de energía, las percepciones definidas que tenemos de nosotros mismos y de nuestro mundo (1998, p. 131).

Es decir, hay un sistema de percepción de mundo que se incorpora en un ser humano hasta que este lo asume como propio, aun cuando actúa contra sus propios intereses, un sistema de entender la realidad que intenta anular y reprimir, de formas muy diversas y complejas, otras formas diferentes de pensar y de vivir.

Resumir el pensamiento hegemónico de Occidente actual es una tarea en exceso compleja. Pero para tener una aproximación válida, se 
puede citar el texto del sociólogo Zygmunt Bauman, Trabajo, consumismo y nuevos pobres. Según Bauman, si el pensamiento burgués de la modernidad del siglo XIX y principios del XX estaba signado por la ética del trabajo (y aquel que no la siguiera, que no se adecuara a esa maquinaria, debía ser excluido), ahora la definición de ideal de vida está marcada por la "estética del consumo": una forma particular de belleza, una constelación de símbolos e identidades, enorme y compleja, pero en el fondo rígida y autoritaria, ha reemplazado tanto nuestra idea del deber ser como la búsqueda de libertad. El sujeto ahora se define por una red de imágenes, de productos y de deseos artificiales que debe consumir eternamente. Quien no puede o no desea consumir, es excluido como peligroso (2000, pp. 27-69).

Pero si el consumo material en general se ha vuelto la nueva hegemonía, las industrias de la cultura (es decir, el sistema industrial y comercial de producción y distribución de significados e ideas) han reemplazado cualquier forma de propaganda autoritaria. Ya no hay una cúpula de intelectuales fabricadores de discursos al servicio de un dictador o de una pequeña aristocracia; hay en cambio todo un mercado infinitamente variado. La impersonal y mercantil industria cultural le ofrece a su público, para su consumo, las más diversas imágenes que le indican cómo definirse a sí mismo y cómo debe interpretar el mundo.

Detrás de la sensación de libertad, de la aparente disolución de los límites, hay una regulación vertical de la vida que emerge de los que dominan el mercado y se extiende al resto de la sociedad, modelando los sujetos. Como en los demás aspectos del consumo, la industria de la cultura define identidades y normaliza la vida de las personas hasta lo más hondo de su ser. Lo que apenas entreveía Pasolini se ha convertido en el sistema generalizado de habitar de los sujetos en la modernidad tardía: la falsa libertad (incluso sexual), que esconde una forma más sutil de dominación.

Los vínculos entre el adoctrinamiento fascista del siglo XX y la estética del consumo que masifica la industria de la cultura no son tan evidentes. Para entender la relación que hay entre ambos discursos, tomemos como ejemplo las siguientes imágenes de la revista para mujeres más importante del franquismo español a comienzos de la posguerra: $Y$, Revista de la mujer nacional sindicalista: 


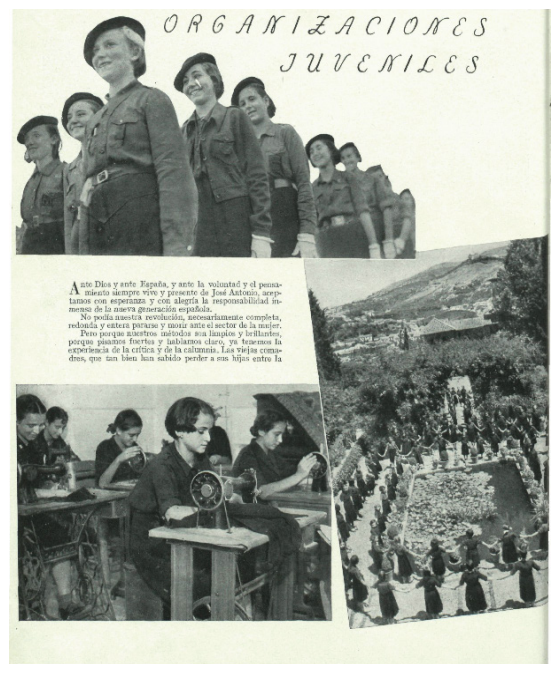

Y, Revista de la mujer nacional sindicalista (1938, p. 8)

El objetivo explícito de la revista era construir una imagen de adoctrinamiento para la mujer franquista. Es decir, establecer un vínculo entre la vida cotidiana de las mujeres, su papel dentro de la sociedad católica tradicional y la disciplina militar necesaria para la obediencia al régimen. La imagen de arriba, tomada de una de las páginas del primer número, es bastante ilustrativa: el trabajo, la actividad lúdica y la instrucción militar son equiparables y pertenecen al mismo sistema; las mujeres, dentro de todas las facetas que el franquismo ha dispuesto para ellas, deben mostrar su obediencia y colaboración al régimen.

Es interesante observar cómo este vínculo de adoctrinamiento político y vida cotidiana se va refinando; de modo que ya en 1945, cuando la urgencia de ganar la guerra ha pasado hace años, la relación disciplina y cotidianidad se ha hecho mucho menos obvia:
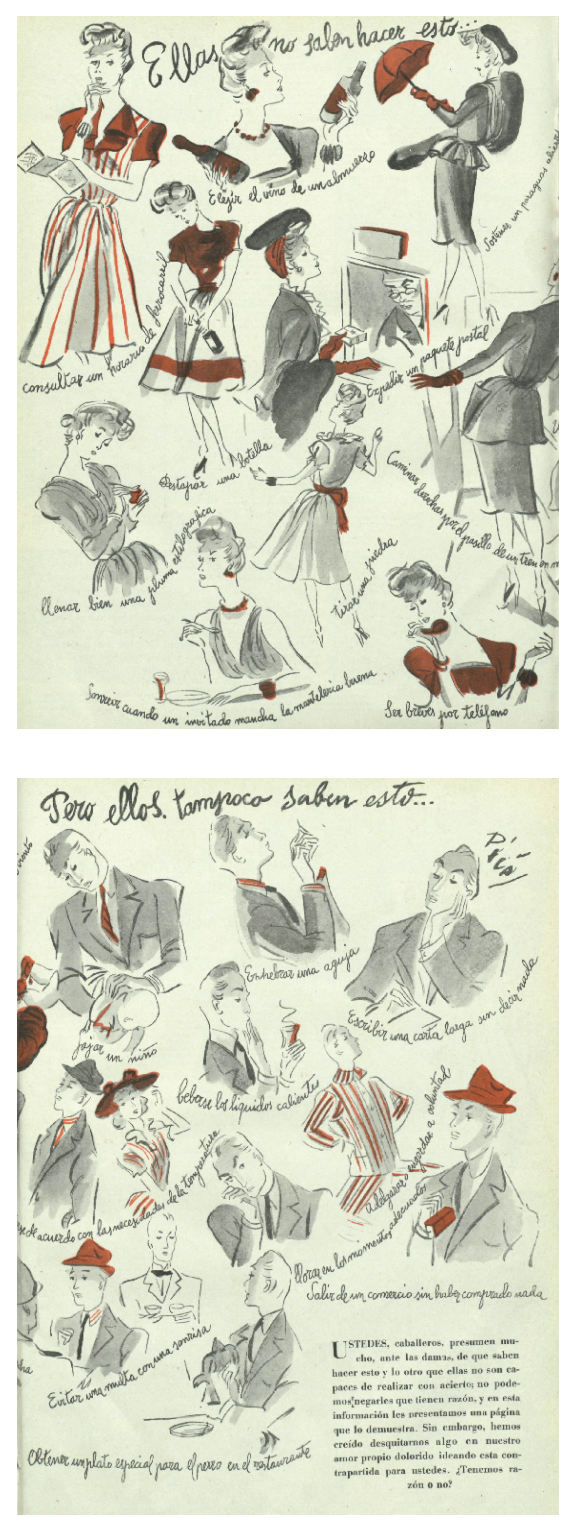

Y, Revista de la mujer nacional sindicalista (1946, pp. 14-15) 
Lo que antes era explícitamente un programa de adoctrinamiento cotidiano-militar de la mujer, se ha convertido en una lista de lo que hombres y mujeres no pueden hacer; es decir, de lo que "naturalmente" son y de lo que están "naturalmente" excluidos. Los hombres, en cuanto hombres, no pueden cuidar niños, usar encantos sociales, llorar, etc.; y las mujeres no pueden tener un sentido práctico, de orientación, orden, etc. En el texto, a través de cierto humor, se busca internalizar el sistema de valores franquista como algo deseable e íntimo.

Por supuesto, el tipo de prejuicios y de órdenes que sobre la mujer operan aquí ya estaban presentes desde antes. Pero el hecho de que una revista que procuraba formar a las mujeres para la obediencia recurriera a este tipo de métodos nos da justamente una idea de cómo el autoritarismo, la dominación del sujeto desde el poder, antecede a los regímenes más obviamente totalitarios. Por otra parte, al comparar esta forma de adoctrinamiento con las revistas y las imágenes de los medios de comunicación actuales, podemos entrever los vínculos entre lo que se propone como inofensivas, intrascendentes y frívolas notas sobre belleza y moda, y un complejo sistema simbólico orientado a la sumisión, al control de la vida cotidiana. Si ya no se les pide a las mujeres ser militaristas en su labor de costura, sí se les exige desear para su vida y para sus cuerpos (y asumir ese deseo como algo natural e incuestionable) una imagen de sujeto al servicio de la sumisión al sistema y una obediencia a la autoridad (ahora difusa) de quienes construyen los ideales que deben seguir. La diferencia entre $Y$ y las revistas modernas es que la autoridad se esconde detrás del deseo. Ya no se dice "debes ser esto" sino "puedes ser lo que quieras, pero solo es deseable ser lo que nosotros decimos que es deseable".

No podemos decir necesariamente que el complejo sistema de significaciones y perspectivas sobre el mundo que constituye la hegemonía de un lugar y tiempo determinado sean necesariamente totalitarias. En efecto, el totalitarismo del siglo $\mathrm{XX}$, con sus gobiernos personalistas y su orientación militarista, no es equiparable con la hegemonía burguesa de la democracia liberal. Sin embargo, si pensamos en el modo en que en general se ha orientado una buena parte de la industria cultural en Occidente, podemos ver que 
muchos elementos del pensamiento autoritario están presentes. Basta observar estas dos imágenes para darse cuenta de cómo, a pesar de las transformaciones, las ideas que sustentaban el autoritarismo siguen rigiendo la construcción de sentido:

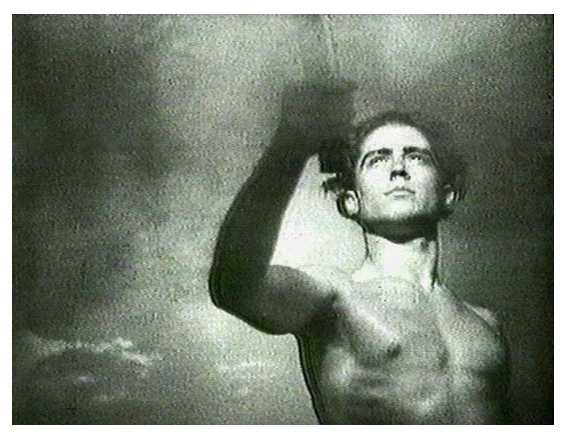

Olympia (Rienfesthal, 1938)

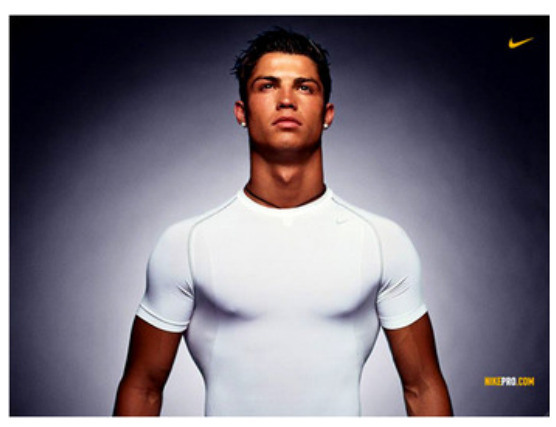

Publicidad con Cristiano Ronaldo (Nike, 2011 )

La primera imagen proviene del documental Olympia, de Leni Rienfesthal, la célebre fotógrafa y cineasta del régimen nazi. La genialidad de Rienfesthal consistió en capturar en imágenes los ideales del nacionalsocialismo: el heroísmo clásico personificado en un individuo, un individuo que sintetizaba a la masa, al pueblo en su pureza, su fuerza y su autenticidad; la multitud convertida en un único cuerpo alegre, fuerte y renovado.

Esta imagen, como el resto del documental, presenta la imagen gloriosa que sedujo a la sociedad alemana y la condujo a la guerra y a la destrucción. Ahora bien, uno puede alegar que ni Rienfesthal era en sí misma nazi ni sus técnicas de construcción de imágenes eran esencialmente totalitarias. Sin embargo, considero que su propuesta de imagen es inseparable del pensamiento autoritario que defendía: el heroísmo, la perfección aséptica del sujeto mirando al horizonte, la fascinación fácil de un hombre idealizado que se convierte en modelo son, en el fondo, arquetipos de pensamiento necesariamente vinculados con el autoritarismo. Son, de hecho, la faceta masculina (e igualmente machista) del adoctrinamiento de las revistas para señoritas. El parecido entre la publicidad de Nike y el documental nazi no es casual ni superficial: ambos basan su éxito en la aceptación de un modo de pensamiento homogeneizador, y a la vez lo reproducen. 
Por supuesto, existen grandes diferencias tanto en lo que pregonan las propagandas totalitarias $y$ las imágenes de la publicidad y la industria cultural actual como en la ideología que las sustenta. Principalmente, hay que decir que ya no se nos pide seguir un gobierno particular ni guardar una lealtad sumisa a un gobernante. Ya no se concibe tampoco que las personas guarden fidelidad a un sistema de ideas diseñado en una mesa de gobierno. Pero, a través del deseo y del consumo, se nos pide aceptar una interpretación del mundo y una imagen de nosotros mismos que permita el funcionamiento de una economía gobernada por el lucro y la exclusión. Como ha señalado lúcidamente Beatriz Sarlo:

$[\ldots]$ no es indispensable creer que todos los resultados de un proceso de expansión y nivelación deben ser celebrados al unísono. En especial si el mercado, que es un espacio seguramente imprescindible de circulación y distribución, agrega a las tendencias igualitaristas un anti-igualitarismo basado en la concentración del poder económico. No es indispensable celebrar la decadencia de la autoridad de los artistas e intelectuales cuando se produce por el asenso de los gerentes de la industria cultural. Parece innecesario decirlo: el mercado cultural no pone en escena una comunidad de libres consumidores $y$ productores (1996, p. 167, énfasis en el original).

Es decir, la aparente diversidad e igualitarismo de la producción y distribución de bienes culturales, a través de la industria de la cultura, esconde un sistema de exclusión basado en el afán de lucro como única guía.

Ahora bien, desde el punto de vista de la construcción de sujeto, hay un sistema de pensamiento particular que la hegemonía de las industrias culturales impone. Por un lado, hay una imagen particular de lo que debe ser y de los papeles que debe ocupar cada sujeto en el mundo; por otro, se nos dice cuál debe ser la idea que se tiene de la sociedad y quiénes están excluidos de ella. Esto significa que, mientras se normaliza y homogeniza al sujeto que permanece en el sistema, a aquellos que no pueden o no quieren pertenecer a él se les niega el carácter de humanos.

Cuando hablamos de esos excluidos o solo nos referimos a los nuevos pobres en cuanto no consumidores (como los define Bauman), sino también a quienes son exterminados, con el beneplácito indiferente de la población mundial, por 
convertirse en un obstáculo para el funcionamiento del sistema.

En el caso de Colombia, la violencia paramilitar en la expansión de las plantaciones de biocombustible es un claro ejemplo de lo anterior. Si bien las causas de la violencia en el país son complejas y requerirían un examen histórico extenso, podemos decir que, en su forma moderna, hay una correlación entre los intereses económicos del poder, la homogenización mediática de la frivolidad, el consumo y el desconocimiento del otro y la impunidad social de las innumerables masacres de campesinos y líderes políticos. Las personas son excluidas hasta el punto de que pueden ser torturadas y eliminadas. No solo no son escuchadas, sino que el horror al que han sido sometidas es tal que no hay ya palabras que puedan expresar sus experiencias.

En el pensamiento autoritario aún en su faceta actual, el otro, en cuanto inútil o estorboso para el sistema, desaparece como ser humano. No solo es eliminado físicamente, sino que su historia es negada. Las formas de violencia de las guerras de baja intensidad que vivimos en Colombia son manifestaciones de los momentos de opresión máxima, de destrucción y de anulación que permite y promueve la alegría de la unión autoritaria. En este sentido, tanto en la forma clásica del totalitarismo del siglo XX como en los nuevos autoritarismos encontramos las dos caras de la anulación del sujeto: el de la homogenización proveniente del discurso aparentemente banal, y aparentemente diverso, pero que en realidad es el discurso de la sumisión; y por otro lado la anulación, discursiva y práctica, de esos otros que no sirven para el proyecto de sistema único que se ha trazado.

\section{Algunas respuestas desde el arte}

¿Por qué preguntarse sobre el arte en una reflexión sobre la pervivencia del pensamiento autoritario? En lugar de responder con una teorización general o un resumen de las infinitas reflexiones que se han hecho al respecto, quisiera hacer algunas aproximaciones fragmentarias a lo que ciertas formas de arte han hecho frente a las hegemonías recientes y al pensamiento autoritario tal como lo conocemos.

Las primeras imágenes corresponden a la grabación del performance Blood Sings/Body Tracks (1974), de la artista cubano-estadounidense Ana Mendieta: 

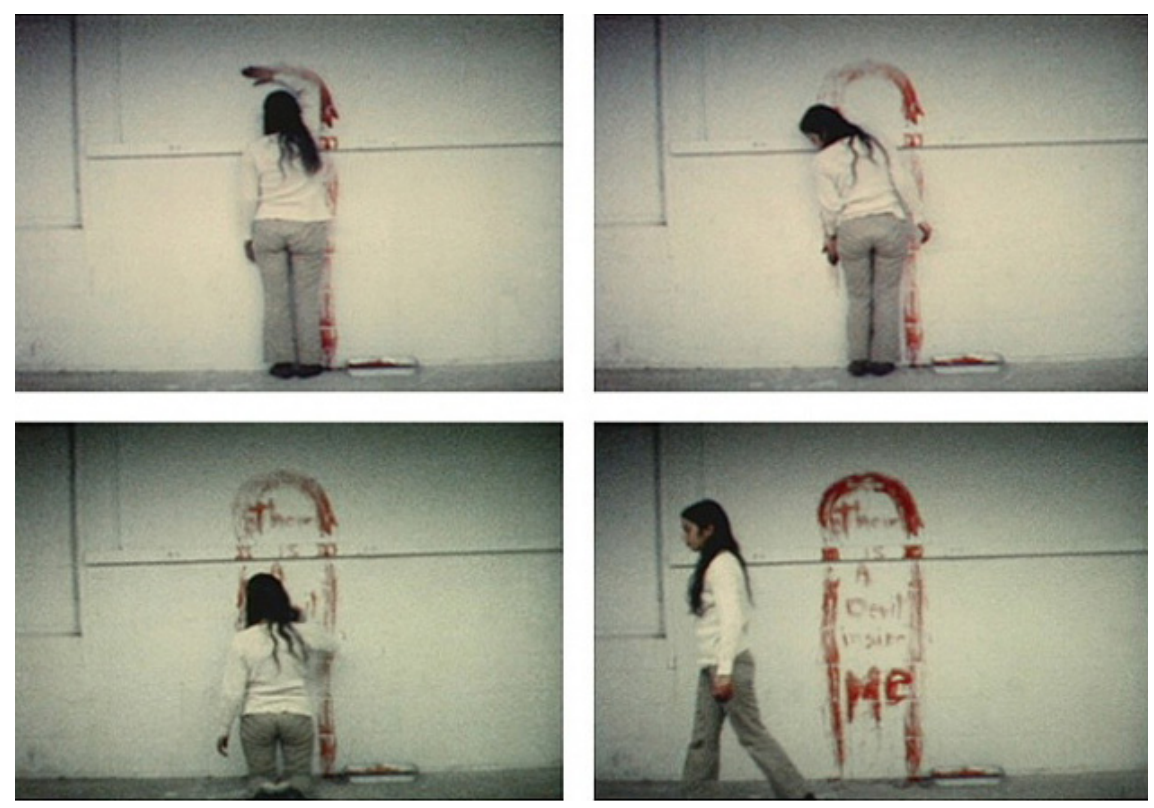

"There is a devil inside me" [Hay un demonio dentro de mí]. En Sin título (Blood Sing \# 1) (Mendieta, 1974a)

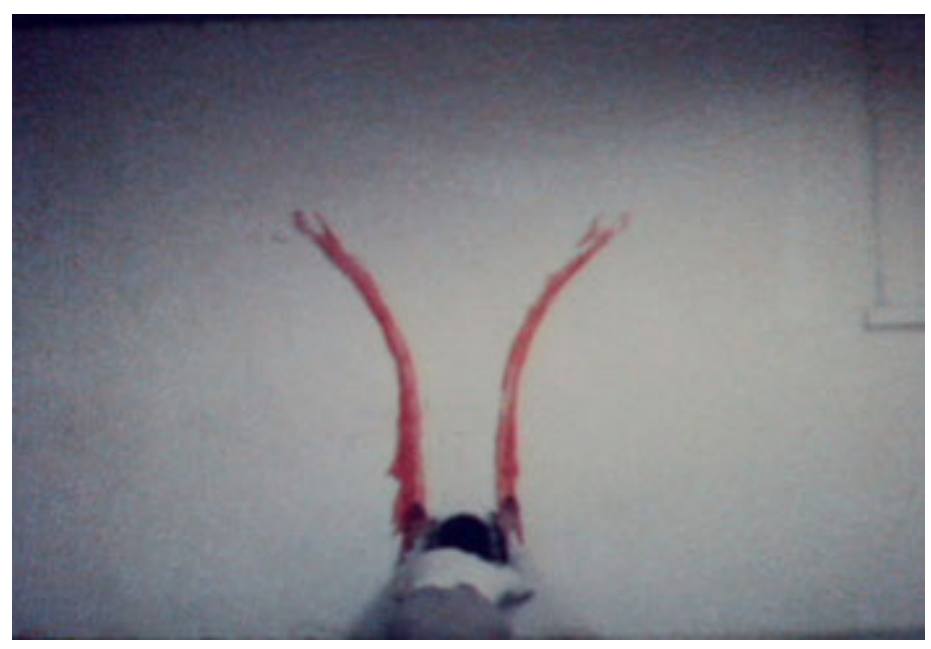

Sin título (Blood Sign \#2) (Mendieta, 1974b)

La artista mancha el cuerpo de corporal de dolor y opresión. Miensangre y deja sus marcas corpora- tras los discursos oficiales ofreles en las paredes. Feminista radical, cen una imagen perfecta y aséptica Mendieta expresa acá su experiencia de la mujer (recordemos $Y$ y sus 
parientes actuales), Mendieta ofrece al público una marca deliberada de suciedad, de violencia y de dolor. El cuerpo femenino, menstrual, violado, destruido, aparece no como comentario sobre el mundo, sino como expresión de lo que el mundo ha hecho en el interior de ella.

Con el trabajo de Mendieta es imposible dejar de lado su dimensión femenina. Sin embargo, en cuanto a lo que nos concierne, la obra de Mendieta apunta simultáneamente en dos direcciones. En primer lugar, está expresando lo que el pensamiento hegemónico autoritario, a través de la estética del consumo, ha hecho con el cuerpo y, por lo tanto, con el sujeto. Todo lo que ha sido reprimido aparece ahora de forma violenta, pues debe denunciar la violencia con la que se ha intentado violentar. El "diablo" que Mendieta lleva dentro proviene justamente de lo que el sistema de significados hegemónicos ha desterrado de la imagen de mujer. Lo demoniaco aparece entonces como lo diferente, como lo que se ha resistido a desaparecer; se presenta como una experiencia de dolor pero a la vez como una manifestación de libertad del sujeto frente al totalitarismo de identidades que impone la estética del consumo.
Aunque con estéticas y propuestas diferentes, podemos entender en un sentido similar la obra del colombiano Luis Caballero. Su propuesta es figurativa, y utiliza técnicas tradicionales de la pintura. Pero la experiencia corporal que presenta es, al igual que en Mendieta, una experiencia de dolor:

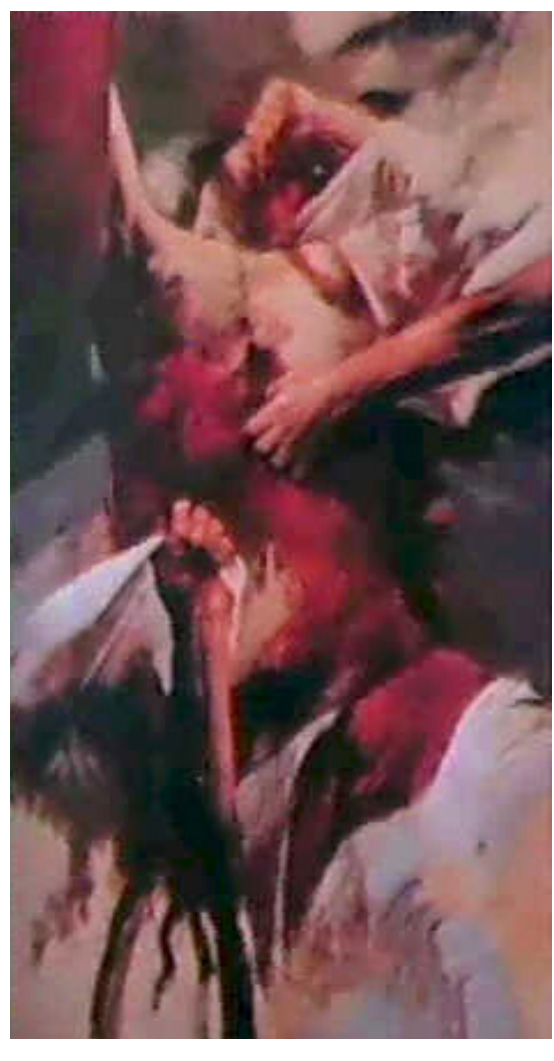

Sin título (Caballero, 1986)

Cuerpos ensangrentados, cuerpos destruidos, arañados; cuerpos masculinos que se presentan desnudos y revelan una doble condición de 
erotismo y vulnerabilidad, ambas negadas del imaginario social de lo masculino. La violencia de su obra no se vincula directamente con una violencia política; su propuesta artística es más sutil: explora la situación de destrucción del sujeto, en el estrado en que lo ha dejado la imposición dominante, la violencia de la asepsia hegemónica.

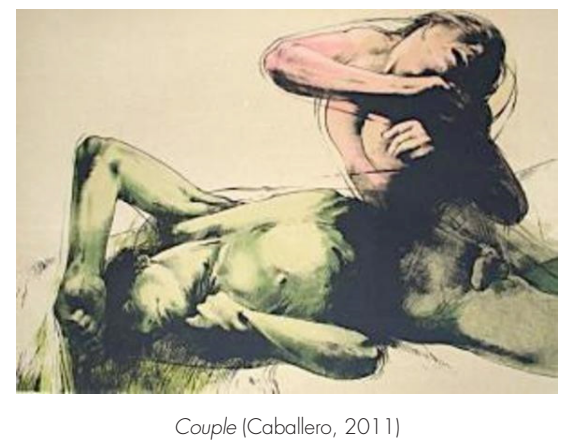

Podría bastar decir que Caballero era homosexual, y ciertamente el componente homoerótico está muy presente en su obra. Pero, al igual que con Mendieta, la fuerza de su propuesta puede leerse como una desviación del poder que se ejerce sobre el cuerpo. En la experiencia de dolor corporal de Caballero emergen las facetas del sujeto que no pueden sobrevivir en los ideales de humanidad y de masculinidad de la publicidad. En la aparente tortura hay un eros más sincero, y una exploración.
A pesar de los distintos que son, tanto en Mendieta como en Caballero encontramos una doble respuesta a la anulación del sujeto propia del discurso autoritario hegemónico: en primer lugar, hay una expresión de dolor interno que se manifiesta como violencia visual. Esa violencia resiste la felicidad artificial impuesta, y manifiesta la anulación que esta esconde. Por otra parte, a través de este dolor hay una exploración y expresión de los aspectos del sujeto que no son reducibles a la estética del consumo: la introspección de ambos artistas, convertida en expresión, sirve para hacer que se sobreviva a la homogenización.

Otra posibilidad que ha explorado el arte, mucho menos subjetiva, consiste en utilizar los elementos de los discursos autoritarios, jugar con ellos y exponerlos. En ese caso, las técnicas de la publicidad, de la campaña masiva, son usadas contra el pensamiento que sustentan. El arte callejero contemporáneo va en su mayoría en esta dirección. Tomemos como ejemplo el caso de Banksy, el exponente más famoso de este arte: 


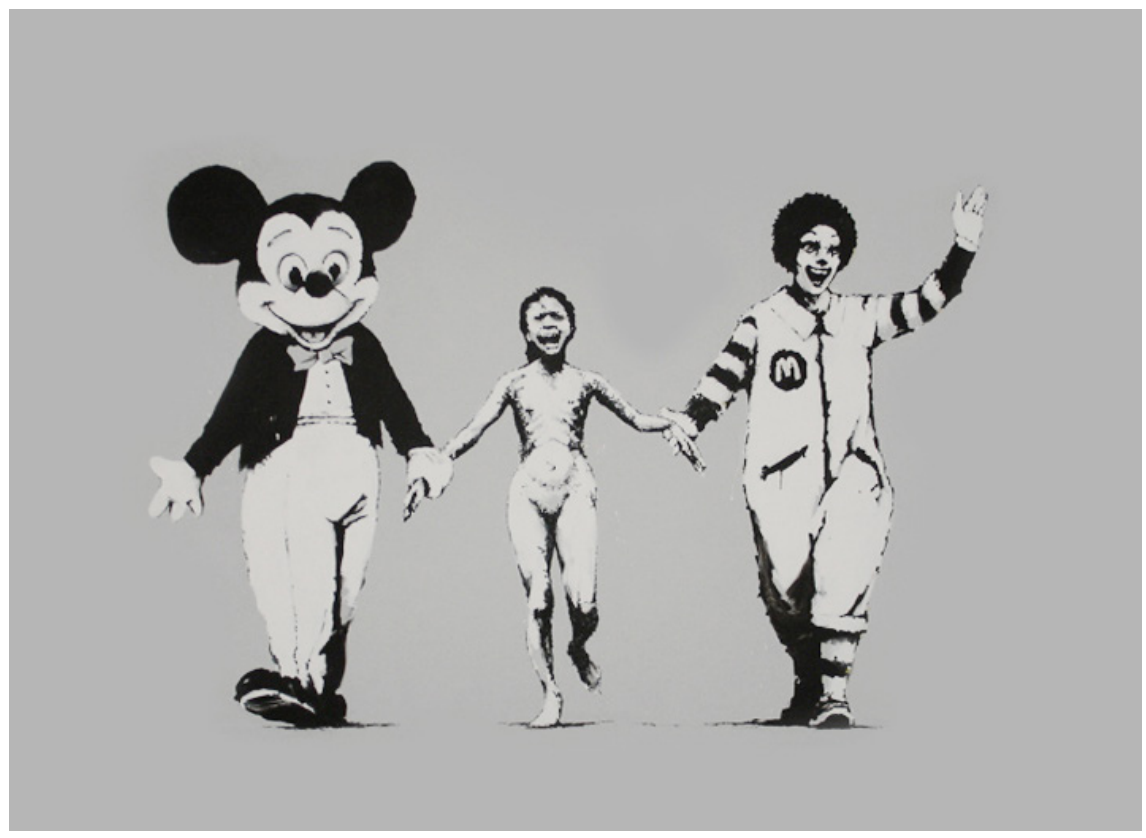

Sin título (Banksy, 2010)

Se trata de un esténcil en el muro de alguna calle (de hecho, de muchas calles). Los tres elementos de la imagen son tan conocidos que han perdido toda fuerza: Mickey Mouse y Ronald McDonald son, por supuesto, el símbolo del imperialismo y del consumismo moderno (ya sea como consumo material puro o como consumo cultural); pero su imagen se repite tanto que, como al himno nacional, es casi imposible prestarles atención. La chica del centro corresponde a la famosa foto que Nick Ut tomó a Kim Phúc después de un bombardeo de napalm durante la guerra de Vietnam. La foto, que se volvió el símbolo de los movimientos pacifistas de los sesenta y setenta, ha sido reproducida tantas veces que ha perdido gran parte de su significado.

Sin embargo, al poner las tres imágenes juntas, Banksy logra que se cuestionen mutuamente y lleva al público a volver a poner su atención sobre ellas. No se trata de un proceso doloroso, aunque la nueva imagen se ocupe del dolor y el horror. El esténcil es principalmente humorístico; pero lo que logra con su humor es, en primer lugar, resaltar la relación entre una forma discursiva aparentemente inocente (Mickey) o una imagen que solo pretende 
vender un producto (Ronald MnDonald), con el tipo de régimen que sustentan. Lo que nos señala Banksy de forma irónica es que aceptar estas figuras es llevar de algún modo de la mano, alegre y amablemente, la tortura del otro. Por otra parte, el uso de las mismas técnicas de la publicidad, de la jovialidad imperante de la estética del consumo, pone al descubierto lo que estas esconden detrás de su aparente inocencia.

Caballero y Mendieta son manifestaciones del arte en cuanto búsqueda de una subjetividad contrahegemónica, y por lo tanto, de una subjetividad que expresa lo que la hegemonía ha hecho con el sujeto. El arte callejero de Banksy no es un arte de exploración subjetiva sino de juego discursivo: sus esténciles parten de la desobediencia, de desestabilizar el discurso autoritario. La resistencia a la hegemonía ocurre en el modo como se transmite su arte (intervenir espacios "ordenados", usándolos como no se debe), pero también en el modo en que usa el discurso hegemónico mismo; la idea es usar los elementos presentes y aceptados, tomar su misma retórica, y luego trastocarla para exponer su mentira. Si en Mendieta y Caballero la resistencia se da desde el interior y desde lo reflexivo, en Banksy se da a partir de la intervención de lo que está en la superficie del discurso autoritario.

Hay una tercera aproximación de la que quisiera ocuparme. Hay cierto tipo de arte que no se ocupa del discurso dominante mismo ni del sujeto que vive en la hegemonía. Este arte busca, en cambio, construir un lenguaje a partir del dolor de ese otro que ha sido excluido de esa hegemonía. Frente al horror del totalitarismo o de los autoritarismos modernos, hay manifestaciones artísticas que buscan dar cuenta de ese horror, expresando lo que de otra manera no se puede expresar. Un ejemplo de esto es el más reciente trabajo de la escultora colombiana Doris Salcedo: Shibboleth. 


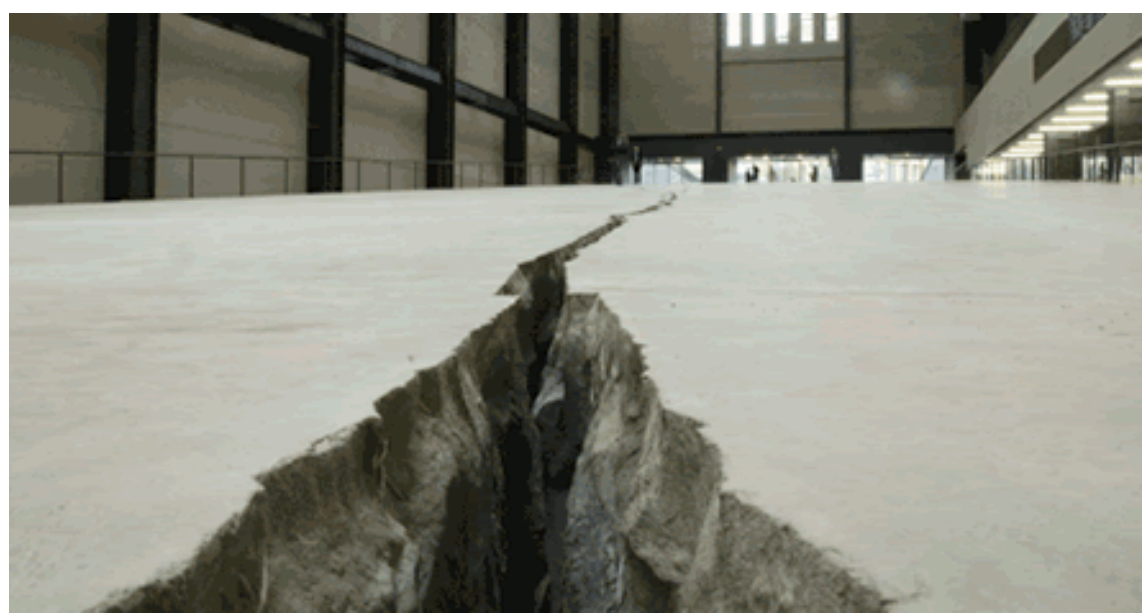

Shibboleth (Salcedo, 2007)

Shibboleth, que en hebreo significa 'espiga' o 'torrente', es una palabra que, por su particular pronunciación, fue usada en tiempos de guerra entre los hebreos para distinguir una tribu de otra, y matar a los enemigos. Hoy en día se usa para designar las marcas lingüísticas que puede usar un grupo (nacional, étnico o social) para distinguir a extranjeros, espías e impostores. Con esta palabra, Salcedo titula la enorme grieta que creó en medio del vestíbulo del museo de arte moderno más importante de Londres.

Según Salcedo (Tate Modern, 2008), la obra fue inspirada en la experiencia del inmigrante en los países del Primer Mundo. El inmigrante es un intruso, una ruptura indeseable que cuestiona y estorba la imagen de supuesta unidad de los países ricos. Desde arriba, desde la perspectiva de quienes caminan en el museo, la grieta es un estorbo, incluso divertido; pero desde dentro de la grieta hay una situación de catástrofe. Asimismo, ocurre con el inmigrante: nunca puede formar parte de la sociedad que lo acoge y lo excluye a la vez, su vida se ve signada por la catástrofe, por ser una grieta; las sociedades que se consideran democráticas y superiores ven cuestionada su supuesta sociedad de consensos y su supuesta superación del odio irracional a lo diferente. La permanencia del horror de lo hegemónico queda así expuesta.

Aun si prescindimos de la interpretación de la artista, la grieta de Shibboleth tiene la fuerza de 
la irrupción, de una ruptura en la tranquilidad del orden establecido. Es también la imposibilidad de emitir un discurso, la imposibilidad que se manifiesta en un lenguaje a la vez violento (el de la catástrofe) y cuidadoso (el de la meticulosidad del trabajo). Es, entonces, un intento de construir otro lenguaje, justamente a partir de la experiencia de ese otro al que el pensamiento autoritario ha despojado de toda posibilidad de comunicación.

\section{Pensamiento artístico}

Las obras que se presentaron acá no agotan las posibilidades discursivas del arte. Las interpretaciones que he esbozado tampoco ahondan en las posibilidades que cada una de estas obras pueden ofrecer. Además, también se han dejado de lado las contradicciones que plantean sus propuestas estéticas. Se podría argumentar, por ejemplo, que cada una de estas obras puede ser absorbida por el establecimiento y asimilarse también al autoritarismo. Tal es el caso de Caballero y Banksy, que de maneras diferentes han sido asimilados a lo decorativo (a la decoración aristocrática y a la industria cultural, respectivamente); o de Mendieta y Salcedo, cuyo hermetismo separa sus productos artísticos de cualquier forma de circulación diferente a los circuitos internacionales elitistas del arte.

Pero, así como en la primera parte de este ensayo me interesaba el pensamiento autoritario y no los regímenes totalitarios específicos, lo que me interesa con respecto a estas obras de arte no son los problemas que plantean en cuanto formas expresivas. Lo que quiero resaltar de estas propuestas artísticas es el tipo de pensamiento que subyace a estas. Los artistas que presenté en la segunda parte buscan maneras de asumir la realidad, la sociedad y su posición en el mundo que desborden los límites de lo que se le impone al sujeto. Podemos discutir la efectividad de su empresa si nos centramos en sus productos o en la recepción que estos han tenido. Pero también podemos entender sus obras como la manifestación de formas de pensamiento alternativas.

Desde esta perspectiva, la interpelación que propongo va más allá de la obra misma y se orienta a la manera de entender el mundo que las hizo posible. Por supuesto, no podemos saber (ni es realmente relevante) qué pensaban exactamente los artistas. Pero sí podemos, 
en cambio, transformar lo que vemos en las obras, nuestra propia lectura de estas, en un momento de reflexión sobre nuestro pensamiento. Así, la interpretación de ellas se vuelve una interpelación a nuestra manera de entender el mundo.

Más allá de la obra de arte como objeto, hay una diversidad de formas de pensamiento que resisten y se oponen al pensamiento autoritario. En la medida que se asumen como propios los momentos de crítica y reflexión de estas formas de pensamiento, se hace posible la exploración de nosotros mismos como sujetos.

Esta exploración del mundo y de nuestra posición en él tiene sentido en la medida en que resista y trascienda la imposición hegemónica. El pensamiento artístico subyacente a ciertas formas de expresión puede tomarse como una interpelación a nuestro propio pensamiento. Lo que se nos pide entonces no es solo intentar comprender una obra, sino asumir nuestra posición en el mundo desde una forma de pensamiento que haga más posible entender al otro, una forma de pensamiento que vaya más allá del velo que las nuevas máscaras autoritarias han impuesto y siguen imponiendo. Tal vez esta sea una manera de oponerse a la alegre barbarie contemporánea.

\section{Referencias}

Banksy. Sin título (Ronald Mcdonald, Mickey Mouse y Phan Thị Kim Phúc) [esténcil]. Arte callejero [en línea]. Consultado el 9 de mayo de 2011 en <http://www.banksy. co.uk/indoors/napalm.html>.

Bauman, Z. (2000). Trabajo, consumismo y nuevos pobres. Barcelona: Gedisa.

Caballero, L. (1986). Sin título [óleo sobre lienzo]. Nueva York: Christie's [en línea]. Consultado el 15 de mayo de 2011 en <http://www.artnet. com/artists/lotdetailpage.aspx?lot_ $\mathrm{id}=$ CCCAC33C58CC59A7 $>$.

Caballero, L. (s. f.). Couple [litografía]. Colección particular [en línea]. Consultado el 10 de mayo de 2011 en <http://www.place-des-arts.com/ en $/$ liste_art.asp?page $=1$ \&pagesize $=$ 25\&n=CABALLERO\&p=Luis\&scri $\mathrm{pt}=$ Listeabc. asp\&add $=508>$.

Y, Revista de la mujer nacional sindicalista (1945, diciembre). Ellas no saben hacer esto... pero ellos tampoco saben esto, 95-96. 
Mendieata, A. (1974a). Untit- Universidad Nacional de Colombia led (Blood Sign \#1) [video]. Nue- (Colección Señal que Cabalgamos). va York: Galerie Lelong [en línea]. Consultado el 15 de mayo de 2011 en <http://www.artnet.com/artwork/426090013/film-stills-fromuntitled-blood-sign-1.html>.

Mendieata, A. (1974b). Untitled (Blood Sign \#2) [video]. Nueva York: Galerie Lelong [en línea]. Consultado el 15 de mayo de 2011 en $<$ http://www.artinfo.com/galleryguide/20297/6832/8731/galerie-lelong-new-york/artwork/ana-mendieta-untitled-blood-sign-2-bodytracks/>.

Nike (2011). Publicidad con Cristiano Ronaldo [en línea]. Consultado el 10 de mayo de 2011 en <http:// www.cristiano-ronaldo.org/nikeadvertisement-191-photo.html>.

Organizaciones Juveniles (1938, febrero). Y, Revista de la mujer nacional sindicalista, 1.

Pasolini, P. P. (2010). Las cenizas de Gramsci y otros escritos. Bogotá:

Riefenstahl, L. (1938). Olympia [documental] [en línea]. Consulado el 5 de mayo de 2011 en $<$ http://www. outsports.com/history/leniriefenstahlreview.htm>.

Salcedo, D. (2007). Shibboleth [escultura-intervención de espacio]. Londres: Tate Modern [en línea]. Consultado el 5 de mayo de 2011 en $<$ http://www.tate.org.uk/modern/ exhibitions/dorissalcedo/default. shtm>.

Sarlo, B. (1999). Escenas de la vida postmoderna: intelectuales, arte y videocultura en la Argentina. Buenos Aires: Ariel.

Tate Modern (2008). The Unilever Series: Doris Salcedo [en línea]. Consultado el 8 de mayo de 2011 en $<$ http://channel.tate.org.uk/tateshots-blog/2007/10/05/issue-8/>.

Williams, R. (2000). Marxismo y literatura. Barcelona: Península. 